\title{
Mulheres e os espaços de poder: uma reflexão sobre a participação feminina nas eleições curitibanas de 2016
}

Marco Takashi Matsuda ${ }^{1}$

- Enviado em 28/08/2017

- Aprovado em 08/12/2017

\section{Introdução}

Historicamente, Curitiba foi cenário de divergências a respeito da participação ativa das mulheres no exercício político e no ingresso aos espaços de poder. O discurso que circulava durante a década de 1930, em vista do sufrágio feminino, muitas vezes era de um posicionamento contra a participação efetiva das mulheres nas tomadas de decisões referentes à vida pública. Tal discurso foi se reconfigurando, e mesmo com muitos avanços conquistados por meio de reivindicações como as feitas por movimentos feministas, ainda se vê necessário posicionar-se a favor de políticas públicas em prol das mulheres. Muitas vezes, esse posicionamento é adotado por candidatas políticas ligadas a movimentos sociais em prol da educação, da saúde e dos direitos voltados à questão das mulheres.

A primeira parte do trabalho se atentará ao comparativo, de modo geral, da participação feminina nos cenários políticos em Curitiba na década de 30 (contexto de conquista do voto feminino), tratando da questão conceitual das relações gênero e poder, com a atualidade, baseando-se em dados sobre o pleito eleitoral de 2016 e em entrevistas das vereadoras concedidas à sessão de notícias do legislativo da Câmara Municipal de Curitiba no ano de 2015. A segunda parte abarcará as questões tratadas na entrevista exclusiva para o presente trabalho, pós pleito de 2016, com algumas das atuais vereadoras do município Katia Dettrich e Fabiane Rosa, seguindo das considerações finais.

\section{O Poder político sob uma perspectiva de gênero: o ontem e o hoje curitibano}

Atualmente as mulheres compõem 52,1\% do eleitorado nacional, 51,9\% do paranaense e 53, $9 \%$ do curitibano. Mesmo com o Código Eleitoral de 1932 e a conquista ao direito de ir às urnas, houveram

\footnotetext{
${ }^{1}$ Graduando em Design pela Universidade Tecnológica Federal do Paraná. e-mail: takashiimatsuda@gmail.com
} 
embates a favor e contra a participação política das mulheres². Segundo o balanço do jornal Correio do Paraná, de 1933, tinha-se o seguinte cenário (FOGGIATO, 2015):

Pudemos observar que a maioria das senhoras e senhoritas da nossa sociedade, obedecendo a uma tradição da sociedade brasileira, são contrárias ao voto feminino. A missão da mulher é no lar, preparando o Brasil de amanhã. E é essa missão que santifica o "sexo formoso". Das 20 enquetes, apenas quatro foram explicitamente favoráveis ao direito conquistado, prestes a ser colocado em prática (CORREIO DO PARANÁ, 1933).

Referidas como o "sexo formoso", "flores do lar", "bello sexo", muitas mulheres da Curitiba da década de 1930, de diferentes extratos sociais, acreditavam que seus esforços deveriam ser direcionados aos cuidados do lar, dos filhos e dos afazeres domésticos, e que o exercício político cabia somente aos homens (FOGGIATO, 2015).

O caso de Rosy de Macedo Pinheiro Lima ilustra bem a realidade curitibana da década de 1930. Neta do comerciante e ervateiro Tobias de Macedo, a jovem que fazia parte da classe dominante tradicional da época, não demonstrava de maneira clara seu apoio à participação feminina na política. Em uma entrevista ao jornal Correio do Paraná sobre a participação da Mulher na política, Rosy fez a seguinte colocação (GOULART, 2016):

O Paraná tem muitos homens capazes pelo patriotismo e, sobretudo, pela honestidade para assumir as rédeas do governo e dirigir os seus destinos. É um cargo ingrato, de sacrifícios e que requer muito esses predicados que enumerei, do seu ocupante. (A MULHER, 1933).

Apesar disso, trilhou carreira como advogada, primeira doutora em Direito Privado, jornalista e como ativista política para com os interesses de seu grupo. E em 1947, foi o primeiro nome feminino associado à Assembleia Legislativa do Paraná, assumindo a primeira suplência na Casa. (GOULART, 2016).

Podemos então afirmar que no imaginário da época as mulheres curitibanas eram entendidas como seres exuberantes fadados aos espaços domésticos, e seguindo certa lógica os homens seriam os detentores dos espaços públicos e ainda dos espaços de poder, como as câmaras municipais, as Assembleias, os Congressos, as delegacias, os tribunais de justiça, dentre outros. Esses traços sociais são permeados pela estrutura histórica sócio cultural do patriarcado, conceito entendido neste trabalho como:

\footnotetext{
2 Os relatos das diferentes mulheres que foram a favor e contra a participação política em Curitiba na década de 1930 podem ser conferidos na íntegra na matéria "1933 - o ano em que as curitibanas foram às urnas". Disponível em http://www.cmc.pr.gov.br/ass_det.php?not=24298\#\&panel1-1. Acesso em: 04/06/ 2017.
} 
(...) organização sexual hierárquica da sociedade tão necessária ao domínio político. Alimenta-se do domínio masculino na estrutura familiar (esfera privada) e na lógica organizacional das instituições políticas (esfera pública) construída a partir de um modelo masculino de dominação (arquétipo viril). (COSTA, 2008).

As delimitações entre espaço público e privado foram construídas socialmente ao longo dos anos nas sociedades ocidentais, sendo que aos homens caberiam as tomadas de decisões, a gestão pública, as ruas, os negócios, enquanto as mulheres deveriam preocupar-se com a beleza, a doçura, os cuidados com a prole e com o ambiente doméstico. Tais distinções naturalizam a divisão de papeis atribuídos a homens e mulheres e reiteram a assimetria de poder $^{3}$ sob uma perspectiva das relações de gênero, conceito aqui tratado como categoria analítica, lançando mão da definição segundo a historiadora Joan Scott: "gênero é um elemento constitutivo das relações sociais baseadas nas diferenças percebidas entre os sexos" (1990, p.86). Ainda citando Scott $(1990$, p.86) tem-se que: "gênero é uma forma primária de dar significado às relações de poder".

Falar em espaços de poder na política pode implicar na noção de disputas de poder as quais também estão imbricadas pelas relações de gênero, como discorre a socióloga política Ana Alice Costa: "Quando falamos relações de Gênero, estamos falando de poder. À medida que as relações existentes entre masculino e feminino são relações desiguais, assimétricas, mantêm a mulher subjugada ao homem e ao domínio patriarcal." (COSTA, 2008).

Havendo uma maioria composta por homens ocupando cargos públicos, no exercício do poder político, sendo que a maioria demográfica nacional é composta por mulheres, haverá também a desigualdade estruturada nas esferas de poder, dada a falta de representatividade em tais espaços ${ }^{4}$, refletindo em disparidades como nas políticas públicas e consequente desproporção na asseguração de direitos das mulheres em relação aos homens.

\footnotetext{
${ }^{3}$ Entende-se o poder conforme COSTA (2008, p.2): “(...) o poder opera em todos os níveis da sociedade, desde as relações interpessoais até o nível estatal. As instituições e estruturas do Estado são elementos dentro de certas esferas de poder, cujas concepções se fundem na complexa rede de relações de força. Nesse sentido, o poder pode ser visto como um aspecto inerente a todas as relações econômicas, sociais e pessoais. Pode-se afirmar que o poder está presente do leito conjugal de um casal a sala presidencial do Palácio do Planalto. Estas relações de poder que operam em distintos níveis estão em constante conflito de interesses". Disponível

em: <http://www.adolescencia.org.br/empower/website/2008/imagens/textos_pdf/Empoderamento.pdf>. Acesso em: 04/06/ 2017.

${ }^{4}$ Exemplo disto é a Câmara Municipal de Curitiba. Segundo uma matéria divulgada pela jornalista Pedritta Marihá Garcia em conjunto com a CMC houve a seguinte situação: "A bancada feminina ocupa apenas 13\% das cadeiras da Câmara Municipal. São cinco, entre 38 vereadores de Curitiba. Nas eleições municipais de 2012, 198 mulheres concorreram a uma dessas vagas, contra 510 homens. As cinco eleitas somaram 38.396 votos, contra 242.695 dos homens. Em votos válidos - no total, foram 975.182 (excluídos os nulos e em branco) - a diferença é ainda maior: as vereadoras tiveram apenas 4,22\% dos votos, enquanto os eles representaram 26,53\%". Disponível em: http://www.cmc.pr.gov.br/ass_det.php?not=24302\#\&panel1-1. Acesso em: 04/06/ 2017.
} 
Conforme Jorge Luiz Bernardi em seu estudo sobre as vereadoras de Curitiba no período de 1947 a 2016 (16 legislaturas), a capital paranaense teve 298 vereadores, sendo apenas 20 mulheres vereadoras, correspondendo a apenas 6,7 \% do total de vereadores que passaram pela Câmara Municipal. Bernardi ainda aponta que após a década de 1990, com a adoção da política de cotas, o número de vereadoras na Câmara praticamente dobrou e que a agenda destas vereadoras era marcada por bandeiras feministas e pelo combate à violência de gênero (BERNARDI, 2016).

Em vista de tais desproporções, as 5 vereadoras curitibanas na gestão 2012/2015 fizeram um apelo por maior participação feminina na política em uma matéria para a Câmara Municipal de Curitiba 5 .

Para a Professora Josete (PT), a desproporcionalidade na disputa e na ocupação de cargos eletivos é um reflexo da cultura machista, que a mulher ainda não conseguiu romper por completo. "Apesar das mulheres estarem conquistando cargos importantes na política, a dificuldade da participação delas é grande. E há, ainda, o próprio preconceito da mulher. Historicamente, o papel do homem é do poder e o espaço da mulher é o doméstico" (GARCIA, 2015).

Garcia (2015) ainda traz outros dados que reafirmam o desequilíbrio da participação de homens e mulheres em outras casas legislativas. No pleito de 2014 para a Assembleia Legislativa do Paraná, de 54 cadeiras disponíveis apenas 4 foram ocupadas por mulheres, enquanto o Congresso Nacional conta com 63 parlamentares mulheres, sendo 51 deputadas federais e 12 senadoras em companhia de 462 deputados e 69 senadores.

Noemia Rocha (PMDB) acredita que mesmo as mulheres sendo a maioria dentre as pessoas votantes, falta o posicionamento para com a própria participação política feminina. "As próprias eleitoras precisam mudar seu conceito. Pode ser segmentado, mas temos que fazer a campanha 'Mulher vota em Mulher'. As mulheres precisam acreditar nas próprias mulheres. Não é possível que as mulheres pensem assim: 'acredito mais no político do que na mulher política'." (GARCIA, 2015).

Em contrapartida, Julieta Reis (DEM) afirma: "O fato de [o candidato] ser mulher não significa que a eleitora vai votar na mulher. Ela tem de ter uma afinidade, uma admiração, uma simpatia e, no caso do cargo de vereador, uma aproximação" (GARCIA, 2015).

Dona Lourdes (PSB) posiciona-se afirmando: “Nossa sociedade ainda está impregnada com certos preconceitos com referência à participação das mulheres em cargos, que anteriormente eram ocupados somente por homens. As mulheres precisam aprender a confiar e delegar poderes ao mesmo gênero. Mas isso é questão de tempo (GARCIA, 2015).

\footnotetext{
${ }^{5}$ Os detalhes da entrevista podem ser conferidos na íntegra em: http://www.cmc.pr.gov.br/ass_det.php?not=24302\#\&panel1-1. Aceso em: 04/06/ 2017.
} 
Já para a vereadora Carla Pimentel (PSC), a falta de participação feminina política está ligada à falta de tradição:

A envergadura das campanhas masculinas é muito maior. Na urna, infelizmente aparece a proporção de uma campanha muito maior e de uma campanha muito modesta. As mulheres encontram candidatos homens com uma projeção, uma estrutura, muito maiores (GARCIA, 2015).

As vereadoras também se posicionam sobre a cota mínima partidária para a candidatura feminina ${ }^{6}$. Josete (PT) critica a atuação das siglas partidárias para com a distribuição de recursos: "Dentro dos partidos não há incentivo para as candidaturas femininas. A nossa participação é figurativa. 0 financiamento é priorizado para os homens" (GARCIA, 2015).

Para Noemia (PMDB) a cota se configura como uma estratégia que visa beneficiar os candidatos homens:

Os partidos precisam atingir a cota de $30 \%$. Se não atingirem a cota, não podem cadastrar os candidatos. Portanto, a busca não significa que o partido quer dar oportunidade, acredita na mulher. Ao contrário, o partido convida as mulheres para viabilizar as candidaturas dos homens (GARCIA, 2015).

Dona Lourdes (PSB) e Carla (PSC) ainda completam a afirmativa:

Os partidos, de modo geral, abrem espaços para as mulheres porque a lei demanda as proporcionalidades de gênero. Mas o preconceito ainda é uma barreira a se desmistificar entre as mulheres". "Mulheres são colocadas como legendeiras em geral. Estão ali para cumprir a cota, cumprir a lei (GARCIA, 2015).

Diferente das colegas, Julieta (DEM) afirma que tais dificuldades se dão em eleições para cargos acima dos de vereadoras e deputadas: "Nas proporcionais, temos vagas sobrando. Não existe possibilidade de uma mulher dizer que quer se candidatar a um cargo de vereadora ou de deputada, e não conseguir. Porque sobra vaga dentro dos partidos" (GARCIA, 2015).

\footnotetext{
${ }^{6}$ As cotas possuem o intento de reparar a inserção tardia das mulheres no âmbito político partidário. Desde 1995 na Lei $n$. 9.100, sofrera alterações em 1997 e em 2009 com a Lei 12.034. Atualmente se prevê que os partidos devem preencher o mínimo de $30 \%$ das candidaturas femininas. Disponível em: http://www.inesc.org.br/biblioteca/publicacoes/artigos/e-perfeitamentepossivel-alcancar-o-cumprimento-de-no-minimo-30-das-cotas-para-mulheres-nas-eleicoes. Aceso em: 4/06/ 2017.
} 
Para as candidatas, as possíveis alternativas para aumentar o número de candidatas e eleitas nas esferas de poder seriam a criação de cota feminina de 50 \% nas vagas eletivas, além de maior engajamento por parte das mulheres para com a vida política. Professora Josete (PT) pondera sobre: "Conquistar a cota não significa participação efetiva, porque por mais que você crie cotas, se não der condição da mulher participar, ela não vai. É preciso garantir a ocupação destas vagas com formação" (GARCIA, 2015).

Para Julieta (DEM) ainda falta disponibilidade e conscientização por parte das mulheres com relação à disputa de cargos políticos: "As mulheres não querem, não tem vontade de participar da vida pública. Os partidos têm dificuldade de preencher a cota dos $30 \%$. Os espaços nas campanhas não faltam, mas é preciso coragem para enfrentar a disputa" (GARCIA, 2015).

Diferentemente, Dona Lourdes (PSB) e Carla (PSC) defendem a necessidade de maiores investimentos para subsidiar o ingresso de mais mulheres na disputa de cargos políticos:

Se uma mulher tem estrutura partidária, financeira ou de preparação política, ela consegue encontrar grandes lugares na política", disse a vereadora do PSC. "A política não é uma ação restrita aos poderes, mas sim da vida. As mulheres precisam entender, desde cedo, que temos os mesmos direitos e deveres que o gênero masculino", finaliza a do PSB. (GARCIA, 2015).

De maneira geral, as vereadoras curitibanas da gestão 2012/2015 acreditam na importância da maior participação feminina nos espaços de poder, seja ocupando cadeiras na Câmara Municipal de Curitiba ou no Congresso Nacional, mas além do aumento no engajamento político feminino, há a necessidade de insumos partidários para proporcionar apoio efetivo para que a participação e a inserção das mulheres nestes espaços não seja meramente figurativa. (GARCIA, 2015).

Por uma maior participação feminina: o cenário político curitibano da atualidade sob a perspectiva das vereadoras Katia Dettrich e Fabiane Rosa

De 2012 até o pleito de 2016, apenas cinco vereadoras ocupavam cadeiras na Câmara Municipal de Curitiba. Após o período eleitoral, 4 vereadoras se reelegeram e outras 4 foram eleitas, totalizando 8 vereadoras, correspondendo a $21,1 \%$ das cadeiras ocupadas na $\mathrm{CMC}$, número histórico para o município. Curitiba ficaria somente atrás de Natal (RN), capital brasileira que mais elegeu vereadoras em 2016, sendo 27,6\% das cadeiras ocupadas por elas na Câmara da cidade (BORDIN, 2016). 
Em âmbito nacional, 7.818 mulheres passaram a ocupar cargos no legislativo, correspondendo a 13,5\% do total. Mesmo com o bom desempenho da capital Curitiba, o Paraná apresentou um índice abaixo da média nacional, sendo que 9.961 mulheres concorreram às vagas legislativas, mas somente 474 foram eleitas, equivalendo a 12,2\% dos eleitos em 2016 no Paraná (BORDIN, 2016).

Os dados do pleito curitibano de 2016 demonstram o sensível avanço na possibilidade de se conquistar mais representatividade, mais acesso aos espaços de poder e mais oportunidades para as mulheres contribuírem de maneira ativa às tomadas de decisões no cenário político local. A respeito da relevância desse assunto, apresentamos as colocações de 2 vereadoras ingressantes na CMC em 2016, a ativista da causa animal, Katia Dettrich, e a professor municipal e também ativista da causa animal, Fabiane Rosa? ${ }^{7}$.

A elaboração do seguinte questionário se deu com o intuito de obter o ponto de vista das vereadoras a respeito do acesso das mulheres aos espaços de poder em Curitiba, sobre a importância das políticas voltadas às mulheres e ainda sobre as possíveis alternativas para que se haja cada vez mais mulheres se envolvendo com questões políticas. Todas as perguntas possibilitavam respostas discursivas, a fim de proporcionar maior liberdade para as entrevistadas se expressarem.

1. Cite, de maneira breve, sua trajetória, atuação e propostas na política curitibana:

Katia: "TITULAR DAS COMISSÕES: Comissão de Legislação, Justiça e Redação, Comissão de Meio Ambiente e Desenvolvimento Sustentável e Ativista dos direitos dos animais a mais de 10 anos, já retirei das ruas mais de 1,200 animais, os mantendo até conseguirem ser adotados".

Fabiane: "Sou professora concursada da Prefeitura Municipal de Curitiba há 23 anos. Desde 2010 sou ativista da causa animal e defensora dos direitos dos animais. Fui eleita defendendo essa bandeira, propondo buscar políticas públicas para beneficiar os animais e acabar com os maus tratos e com o abandono".

Ambas candidatas levantaram suas bandeiras em prol da causa animal e se elegeram como representantes políticas que atuam no combate aos maus tratos contra os animais.

2. O que te motivou a ingressar na carreira política? Quais foram suas principais propostas para a candidatura?

\footnotetext{
7 É importante salientar que o questionário de entrevista desta pesquisa foi enviado via correio eletrônico à todas as 8 atuais vereadoras de Curitiba, porém, somente as vereadoras Katia e Fabiane haviam respondido às perguntas até o fechamento deste trabalho.
} 
Katia: "Fui motivada a entrar para carreira política em 2012 quando tentei me eleger pela primeira vez graças ao meu amor pelos animais, indignada e vendo a necessidade de políticas públicas para eles, não pensei duas vezes. Estou trabalhando pela aprovação de meus projetos que foram promessa de campanha e já foram protocolados como:

-Censo amostral de animais.

-Programa Veterinário Mirim que visa dar as crianças da rede municipal de ensino uma conscientização de como tratar os animais.

-Redução de ISS em até 50\% para clínicas veterinárias que atenderem animais de baixa renda.

-Projeto para tratar pessoas com transtorno acumulador compulsivo".

Fabiane: "Entrei na política para fazer o que não conseguia como ativista, como protetora: mudar a situação em que se encontram milhares de cães abandonados em Curitiba. É por isso que entrei na política. Para propor leis que minimizem esse sofrimento, que garantam os direitos dos animais, que punam aqueles que maltratam animais. Luto por políticas de castração para evitar que mais cães e gatos sejam abandonados. Não só isso, como vereadora tenho obrigação de fiscalizar a Prefeitura e cobrar que as leis que já existem sejam cumpridas. Essas foram as minhas propostas: lutar pela defesa animal em todos os seus aspectos".

Nota-se, pelos discursos, de ambas vereadoras o forte apelo emocional para com suas propostas, além da preocupação com políticas públicas que interfiram de maneira eficaz nas condições dos animais abandonados e que previnam futuros maus tratos.

3. Qual a sua visão a respeito do cenário político em Curitiba na atualidade em torno das questões referentes às mulheres brasileiras?

Katia: "Acredito que a política deve ser feita com a presença da mulher no poder. Em tempos de luta por direitos iguais, a vejo com bons olhos o crescimento da bancada feminina na Câmara de Curitiba e em todo Brasil". 
Fabiane: "Somos oito mulheres eleitas vereadoras. É a maior bancada feminina da história de Curitiba. Nesses seis meses de legislatura, muitos projetos de lei que visam defender e dar amparo às mulheres foram protocolados e estão sendo debatidos. Vejo, portanto, que o cenário é extremamente favorável nessa questão".

As candidatas se mostram otimistas a respeito do aumento participativo das mulheres na política local e ainda acreditam que o contexto atual propicia mudanças favoráveis para a atuação das mulheres nas tomadas de decisões.

4. Você acredita na importância da ocupação por parte das mulheres nos espaços de poder?

Fabiane: "Com certeza. Falei que somos oito mulheres vereadoras na Câmara. Poderíamos e deveríamos ser mais. Temos 30 homens vereadores. As mulheres precisam participar mais da política. Somos competentes e preparadas para atuar em qualquer esfera, em qualquer segmento. Não é mais possível aceitarmos diferenciações salariais por sermos mulheres. Somos maioria nessa país".

Katia: "Acredito na ocupação das mulheres nos espaços de poder, pois elas representam uma nova visão da política brasileira".

As vereadoras acreditam na importância das mulheres ocuparem os espaços públicos, pois representam a mudança na política. Assim, as mulheres são tão capacitadas quanto os homens a exercer quaisquer funções. Reitera-se o apelo de Fabiane Rosa a favor de salários equivalentes para mulheres e homens no Brasil.

5. Você já sofreu algum tipo de discriminação por ser mulher ocupante de um cargo político? Se sim, poderia relatar sobre?

Katia: "Felizmente nunca sofri nenhum tipo de discriminação".

Fabiane: "As mulheres sofrem discriminação em qualquer segmento, não apenas na política. Estou ocupando o cargo de vereadora há apenas seis meses. Já pude sentir as dificuldades em ocupar um cargo político. Ser mulher na política é ainda mais difícil. Não posso dizer que me senti discriminada, mas posso assegurar que facilidades também não tive. Mas eu não me deixo intimidar. Sou corajosa e falo alto. Não fujo de uma boa briga. Sou autora do projeto mais polêmico Não fujo de uma boa briga. Sou autora do projeto mais polêmico da Câmara, o que proíbe a soltura de fogos de artifício com estampido em Curitiba. Sofro pressões da indústria de fogos e, também, de vereadores simpáticos a essa indústria. Não cedi em 
nenhum momento. Ao contrário, levei essa discussão para as redes sociais, para a imprensa e para a sociedade. Tenho mais apoio do que críticas. O projeto está tramitando. Já foi aprovado pela Comissão de Legislação e deve ir a plenário nos próximos meses, para tristeza dos que defendem essa prática atrasada e nociva. Ouvi muitos gritos, mas gritei mais alto".

Enquanto Katia alegou não ter sido alvo de discriminações por ser mulher em um cargo político, Fabiane posicionou-se de maneira firme sobre a questão da mulher para com a discriminação sob uma perspectiva de gênero. Além de relatar as dificuldades dentro da vida política, se afirma como mulher ativa e pronta para mediar discussões em diferentes âmbitos.

6. Na eleição de 2016 houve um sensível aumento no número de mulheres ocupando cargos de vereadoras na Câmara Municipal de Curitiba. Qual a sua opinião sobre esse dado e quais são suas colocações sobre esse fato.

Katia: "Vejo com muita alegria o aumento da bancada feminina na Câmara. Acredito que seja uma boa chance para se fazer políticas públicas para as mulheres".

Fabiane: "Como já respondi, somos a maior bancada feminina da história da cidade. Isso é extremamente saudável para a democracia, embora ainda sejamos poucas. Quem sabe na próxima eleição tenham mais mulheres disputando e tenhamos ainda mais representantes na Câmara".

Katia enxerga o sensível aumento da bancada feminina na Câmara curitibana como uma oportunidade de se promoverem mais políticas públicas voltadas às mulheres. Enquanto Fabiane ressalta que o fato de 2016 é um ponto positive para o exercício democrático e vê a possibilidade do aumento de representantes mulheres na CMC.

7. Você acredita que falta oportunidades para as mulheres ingressarem nos espaços de poder em Curitiba, como por exemplo a Câmara Municipal?

Katia: "Não acredito na falta de oportunidades, mas sim na falta de interesse por parte da população como um todo".

Fabiane: "Acho que não é uma questão de faltar oportunidades. Você chega à Câmara através do voto popular. É preciso, portanto, que se candidate. O que acontece é que temos poucas mulheres dispostas a se candidatar. A proporção é desigual nesse sentido, mesmo sendo obrigatória a reserva de $30 \%$ de vagas 
para mulheres numa chapa eleitoral. Isso não é limitador. É o mínimo. Podemos ter uma chapa com $60 \%$ de mulheres por exemplo, basta que se candidatem".

Ambas vereadoras não acreditam que haja a falta de oportunidades para as mulheres ingressarem nos espaços de poder em Curitiba. Elas apontam a falta de interesse das mulheres para com as candidaturas como fator relevante para a falta de mulheres em espaços como a Câmara Municipal.

8. Quais alternativas você poderia citar para que houvesse o aumento do número de mulheres com acesso aos espaços de poder em Curitiba?

Katia: "A única maneira do número de mulheres crescer nas casas legislativas do país, é elas se unirem e principalmente se interessarem e lutarem para mudar a velha política que tanto nos envergonha atualmente".

Fabiane: "A melhor alternativa é as mulheres se envolverem mais com a política. Tudo que cerca o nosso dia a dia é fruto da política. Os preços nos supermercados, os impostos que pagamos, as leis que temos que respeitar, enfim, tudo é política. Por que, então, não ir pra rua, não brigar pelos nossos direitos, não cobrar o que é nosso? Temos muitas mulheres preparadas para exercer um cargo público, seja por meio de um mandato eletivo ou em funções importantes da administração pública".

As vereadoras novamente evidenciam a importância da tomada de consciência por parte das mulheres a fim de se desenvolver maior interesse sobre as questões políticas, visto que estas permeiam seus cotidianos e que muitas mulheres estão aptas a exercer funções nas esferas de poder. Também afirmam a necessidade da união entre as mulheres para contribuir com a mudança do cenário político atual.

\section{Considerações Finais}

Mesmo na década de 1930, com as mobilizações em prol do sufragismo feminino, discursos marcados por traços ligados ao patriarcado permeavam diversos extratos sociais, no tocante a respeito da participação das mulheres na política curitibana.

Apesar disso, no decorrer dos anos, outros discursos também se fizeram ouvir, como as reivindicações por parte das mulheres a favor de melhores condições de trabalho, ou mesmo melhores condições de sobrevivência se levarmos em consideração os altos índices de feminicídios que ocorrem no país, conforme os dados apresentados pela Organização das Nações Unidas: 
No Brasil, a taxa de feminicídios é de 4,8 para 100 mil mulheres - a quinta maior no mundo, segundo dados da Organização Mundial da Saúde (OMS). Em 2015, o Mapa da Violência sobre homicídios entre o público feminino revelou que, de 2003 a 2013, o número de assassinatos de mulheres negras cresceu 54\%, passando de 1.864 para 2.875 . (ONU MULHERES BRASIL, 2016).

Além de tantos outros fatores que contribuem para as assimetrias entre gêneros na sociedade brasileira, o pouco acesso das mulheres aos espaços de poder também está imbricado com a escassez de políticas públicas voltadas ao público feminino, mas não somente na parte legislativa como também na executiva, pois é necessário que se haja a fiscalização do cumprimento das leis e dos projetos já existentes para $o$ atendimento das mulheres.

As falas das vereadoras entrevistadas revelam que ainda se vê necessário fomentar mais discussões a fim de despertar maior engajamento das mulheres para adentrarem cada vez mais as disputas políticas. Não somente o esforço por parte do público feminino, mas também por parte de outras instâncias como os partidos políticos, em creditar suas candidatas e fornecer a elas os insumos necessários para a construção de uma campanha que de fato projete a imagem da mulher como um agente político habilitado tanto quanto o homem. E mesmo dentre as eleitoras e os eleitores, se faz necessário o aumento dos debates sobre os indivíduos votados, repensando o fato do eleitorado ser composto em maioria pelas mulheres, mas sua representação nos espaços de poder ainda é muito desigual em comparação com a masculina.

O presente trabalho levou em consideração a importância do tratamento das questões de gênero como uma breve forma de analisar os discursos em torno da participação feminina na política curitibana, que conforme SCOTT (1990), gênero é uma categoria útil para analisar historicamente as relações sociais. Outros fatores devem ser evidenciados em trabalhos futuros, como as relações nepotistas e o acesso de determinadas mulheres aos espaços de poder, levando em consideração a interseccionalidade de raça, classe e geração nestes trabalhos.

\section{Referências}

BERNARDI, J. L. Vereadoras de Curitiba: Poder Familiar e Cotas de Gênero. In: OLIVEIRA, R. C. (Org.). Nepotismo, Parentesco e Mulheres. Curitiba-PR: RM Editores, 2016. p. 335-271.

BORDIN, Laura Beal. Com número histórico, Curitiba é 2a capital que mais elegeu mulheres para o legislativo. Gazeta do Povo, 2016. Disponível em: <http://www.gazetadopovo.com.br/vida- 
publica/eleicoes/2016/com-numero-historico-curitiba-e-a-2-capital-que-mais-elegeu-mulheres-para-olegislativo-akf7cnjj711ju79d9gjzzd7tc. Acesso em: 18 de jun. 2017.

CENTRO FEMINISTA DE ESTUDOS E ASSESSORIA. 30\% das Cota para Mulheres nas Eleições. 2010. Disponível em: <http://www.inesc.org.br/biblioteca/publicacoes/artigos/e-perfeitamente-possivelalcancar-o-cumprimento-de-no-minimo-30-das-cotas-para-mulheres-nas-eleicoes $>$. Acesso em: 4 de jun. 2017.

COSTA, Ana Alice. Gênero, poder e empoderamento das mulheres. 2008. Disponível em: <http://www.adolescencia.org.br/empower/website/2008/imagens/textos_pdf/Empoderamento.pdf>. Acesso em: 4 de jun. 2017.

FOGGIATO, Fernanda. 1933: O ano em que as curitibanas foram às urnas. Câmara Municipal de Curitiba. 16 de Mar. 2015. Disponível em: <http://www.cmc.pr.gov.br/ass_det.php?not=24298\#\&panel1-1> . Acesso em: 4 de jun. 2017.

GARCIA, Pedritta Marihá. Vereadoras pedem maior participação feminina na política. Câmara Municipal de Curitiba. 6 de Mar. 2015. Disponível em: <http://www.cmc.pr.gov.br/ass_det.php?not=24302\#\&panel1-1>. Acesso em: 4 de jun. 2017.

GOULART, Mônica Harrich Silva. As mulheres na ALEP: Uma abordagem prosopográfica. In: OLIVEIRA, R. C. (Org.). Nepotismo, Parentesco e Mulheres. Curitiba-PR: RM Editores, 2016. p. 266-271.

ONU MULHERES BRASIL. ONU: Taxa de feminicídios no Brasil é quinta maior do mundo; diretrizes nacionais buscam solução. 2016. Disponível em: <https://nacoesunidas.org/onu-feminicidio-brasil-quinto-maiormundo-diretrizes-nacionais-buscam-solucao/>. Acesso em: 19 de jun. 2017.

SCOTT, Joan. Gênero: uma categoria útil de análise histórica. Educação e Realidade: Porto Alegre, 1990. p. 86. 